\title{
Funciones psicológicas y tratamiento de las rumiaciones obsesivas en el duelo
}

RESUMEN: Se describen distintas funciones psicológicas de las rumiaciones obsesivas, factores de riesgo de complicaciones y una aproximación de tratamiento basada en el modelo de Psicoterapia Integrativa

PALABRAS CLAVE: Estilo rumiativo, obsesiones, duelo, Psicoterapia Integrativa.
RESUMEN: We describe different Psychological functions of ruminative obsessions, risk factors and a treatment approach based on the Integrative Psychotherapy model.

KEY WORDS: Ruminative coping, obsessive thoughts, bereavement, Integrative Psychotherapy.

La muerte de un ser querido provoca un conjunto de reacciones emocionales difíciles y dolorosas a las que las personas en duelo deben responder. Aunque para la mayoría de los dolientes la intensidad de estas reacciones disminuye con el tiempo, una minoría desarrolla complicaciones que afectan a su salud mental y física. Llamamos estilos de afrontamiento a las distintas maneras o estrategias que la persona utiliza, consciente y muy a menudo inconscientemente, para reducir, manejar y sobrevivir a esta sintomatología física, mental y emocional natural en el duelo.

Los mecanismos de afrontamiento son esfuerzos o procesos constantemente cambiantes de los que la persona se sirve para responder a demandas internas o externas que son percibidas como excesivas para sus propios recursos (1). No se trata de caracteres rígidos, sino de procesos activos cuyo objetivo es manejar una situación de amenaza, estrés o pérdida de la mejor manera posible. Esta actividad puede tomar distintas formas: Moss y Shaffer (2) en un trabajo temprano realizado sobre el afrontamiento de crisis en la vida, distinguen entre estilos enfocados en la valoración o cognitivos, estilos enfocados a la resolución de problemas o conductuales, y estilos de afrontamiento centrados en las emociones. El que una persona responda de una manera u otra frente a una situación de amenaza, trauma o pérdida va a depender de variables internas como factores de desarrollo, rasgos de personalidad, género, experiencias previas de pérdidas y otros; pero también de variables externas como la propia naturaleza del trauma y la percepción de disponibilidad de apoyo en el entorno.

El estilo rumiativo es un mecanismo cognitivo de afrontamiento que se caracteriza porque el doliente focaliza la atención en los aspectos difíciles o negativos de una manera repetitiva y pasiva (3). En varios estudios realizados en muestras de personas en duelo con estilos de afrontamiento rumiativos se han descrito 
altos niveles de incidencia y severidad de depresión, cronificación del proceso y un aumento de la sintomatología, especialmente la asociada al estrés postraumático. Por tanto, según este modelo, el estilo rumiativo es maladaptativo y predice un desajuste y menor calidad de vida en el doliente (4-5). Otros estudios, sin embargo, sugieren lo contrario: que esta focalización cognitiva persistente en pensamientos o sentimientos relacionados con el ser querido muerto y el impacto que su pérdida tiene en la vida del doliente es una reacción común en el duelo cuyo propósito y resultado es muy individual y que puede ser adaptativa (6).

Aunque en algunos estadios del duelo la rumiación correlaciona negativamente con el bienestar general, eso no significa que rumiar sea siempre improductivo. La revisión repetitiva del evento traumático puede ayudar a las personas a manejar el impacto emocional y contribuir a hallar un nuevo sentido a la pérdida. Esta construcción de nuevos significados contribuye a desarrollar un nuevo encuadre de referencia o visión del mundo que incorpora el evento traumático (7) y por tanto facilita una buena resolución del duelo.

Michael y Zinder (8), en un estudio reciente realizado con estudiantes universitarios en duelo, llegan a proponer denominar rumiación al estilo maladaptativo que no produce alivio en el tiempo, y proceso cognitivo al proceso adaptativo o pensamientos repetitivos productivos focalizados en la resolución, como según estos autores, lo que marca la diferencia entre un estilo u otro es si el proceso lleva o no a la posibilidad de encontrar un nuevo sentido a la muerte, o un significado que el doliente pueda incorporar. Entonces esta posibilidad se asocia con un decrecimiento de la rumiación derivando en una mejora del bienestar psicológico. En este ar-tículo se propone una descripción más amplia del estilo rumiativo, incluyendo el pensamiento obsesivo como rasgo central y característico. Se identifican las funciones psicológicas de estas defensas desde una visión adaptativa, y se propone un tratamiento desde el modelo y aportaciones de la Psicoterapia Integrativa.

\section{Características del pensamiento obsesivo}

\section{Carácter repetitivo.}

Falta de expresión de afectos.

Falta de acción, pasividad.

Pérdida de visión general.

Soledad.

El pensamiento obsesivo como defensa o estilo de afrontamiento cognitivo, respuesta natural ante la pérdida de un ser querido (Tabla $n .^{\circ} 1$ ) se manifiesta como 
ORIGINALES Y REVISIONES

un monólogo verbal interior donde la persona en duelo está hablando consigo misma, con otro o con algo, a quien pregunta, a quien acusa, a quien responsabiliza o culpabiliza, de quien quiere vengarse, o bien da vueltas y más vueltas a detalles sobre alguna situación concreta buscando elementos, respuestas o significados. Las rumiaciones obsesivas en el duelo se dan a menudo en forma de pensamientos intrusivos, fuera de control, como una voz ajena. Suelen tener formas como: «Y si...», «si él no hubiera...», «si pudiera volver atrás», «ellos son los responsables», «ójala le pase algo», «tendría que denunciarles», «es mi culpa», «si no hubiera ido ahí», «ipor qué no nos dimos cuenta?», «no puedo vivir sin él», «no puedo seguir así», etc., que en forma repetitiva, señalan situaciones, elementos o aspectos inaceptables acerca de las circunstancias de la muerte o de la relación perdida y sus consecuencias.

El pensamiento obsesivo se configura siempre alrededor de una cuestión en forma de búsqueda: la exploración de elementos circunstanciales que expliquen o justifiquen la causa de la muerte (¿Por qué?, ¿qué pasó?, ¿cómo fue?); fijaciones en detalles no necesariamente relevantes ( ${ }^{Y} Y$ si?); identificación de responsables de la muerte, ya sean otros, un colectivo, la misma persona en duelo o la persona fallecida (¿Quién?); focalización en síntomas negativos y sus posibles causas y consecuencias; e intento de búsqueda de significados sobre el porqué o el para qué de la muerte (¿Por qué?, ¿para qué?).

La etología nos aporta ejemplos de comportamientos obsesivos en animales como respuesta a dos tendencias impulsivas en conflicto: por ejemplo, la necesidad de defender el territorio y la necesidad de escapar de una amenaza de peligro (9). La característica oscilación descrita por M. Horowitz (10) podría interpretarse etiológicamente como las manifestaciones entre distintos polos opuestos de la situación o conflicto. De la misma manera, el pensamiento obsesivo en la persona en duelo alterna rápidamente entre, por ejemplo, manifestaciones de responsabilidad por no haber percibido el peligro en la situación aparente que causó la muerte, que son sustituidas inmediatamente por expresiones de inocencia con el fin de protegerse del dolor de la culpa. Es decir, bajo cada expresión subyacen dos necesidades en conflicto, lo que explica su carácter oscilatorio. Muy a menudo, en el proceso de duelo, la oscilación se da entre más de dos polos: el pensamiento de culpa por no haberse dado cuenta del peligro es sustituido por un rápido pensamiento de ira hacia el médico que lo trataba; este pensamiento es a su vez sustituido rápidamente por una sospecha acerca de la información respecto del diagnóstico, que es a su vez reemplazado de nuevo por la duda de si la muerte podía haber sido evitada de alguna manera. Un pensamiento deshace el otro que es deshecho a su vez por uno nuevo. Como la circularidad se hace de forma muy rápida, la persona no llega a sentir ninguna emoción fuerte y permanece en estado de ansiedad o confusión. Esta falta de expresión 
de afectos es otra de las características del pensamiento obsesivo: no hay amor ni dolor, sino una detención en lo cognitivo, pues no hay objeto de contacto real desde lo emocional. De hecho, si se expresaran las emociones encubiertas (llorar, chillar, enfadarse) el pensamiento obsesivo pararía. Esta falta de emoción natural y espontánea va acompañada de una falta de acción. Los pensamientos obsesivos son muy invalidantes: son sueños, fantasías acerca de la realidad, suposiciones, ideas, y su propósito parece mantenerse ahí. Las personas con estilos de afrontamiento obsesivos se anclan en lo mental sin llegar a expresar las emociones subyacentes. No hay un compromiso activo en la búsqueda de soluciones: piensan en ello pero no llegan a realizar la acción resolutiva. Es muy difícil tomar decisiones porque no hay un proceso racional de discernimiento: el propio intento desesperado de buscar respuesta parece obliterar la posibilidad de hallarla, por eso el pensamiento obsesivo va acompañado de una pasividad característica.

Por otra parte, en la obsesión, la experiencia de la realidad es mental y suele estar focalizada sólo en algún aspecto concreto de ésta: se produce una pérdida de la visión general o global de la situación. El pensamiento se fija en algún detalle, aspecto o momento, a veces inconsecuente, y el resto de elementos vitales está ausente, no hay visión de conjunto sobre la situación. Se trata de una fijación cognitiva característicamente rígida e inflexible. Esta falta de acción, y esta rigidez, además van acompañadas de la sensación de soledad. La persona tiende al aislamiento, a no conectar con el entorno ni consigo mismo: mira al suelo, se habla a sí misma o a las circunstancias, pero sin contacto con lo que le rodea ni contacto interno con la experiencia subjetiva de lo que está contando. El mecanismo obsesivo es una forma de muerte, muerte para uno mismo, muerte para las relaciones con los demás, muerte para la vida.

\section{Funciones psicológicas del pensamiento obsesivo}

En relación con el trauma de la muerte: Mejora de la predictibilidad.

Búsqueda de un significado.

En relación con la vinculación: Reparación de la culpa.

Continuidad de la vinculación.

En relación con la negación del dolor: Sentido de control y estabilidad.

Protección o evitación del dolor

Estabilidad de ego frágil y dependiente.

«Mi hija murió en un incendio, me dijeron que no fue provocado, que fue un accidente, pero yo no lo sé. No me dejaron ver el lugar, ni me dejaron ver el cuerpo. La policía cerró la casa y ya nunca pude entrar. Me pregunto una y otra 
ORIGINALES Y REVISIONES

vez qué sucedió, dónde hallaron su cuerpo, cómo estaba, por qué no pudo salvarse. Sus amigos pudieron hacerlo, ¿por qué ella no? No me lo puedo sacar de la cabeza. Creo que me ocultan algo. Voy al cementerio cada semana, pero no me ayuda, doy vueltas y más vueltas, me duele la cabeza y no puedo dormir». Pilar.

Tradicionalmente los comportamientos obsesivos han sido vistos como un intento de predicción ante situaciones de caos. Niños que han crecido en ambientes de desestructuración o en familias impredecibles desarrollan conductas obsesivas como un esfuerzo para identificar y predecir amenazas, y dar un sentido de control y orden a la situación (11). También en vivencias de trauma o negligencia, las preocupaciones obsesivas pueden manifestarse como una forma de resolver o hacer algo para dar estructura y sentido a la experiencia. En ausencia o ruptura de relaciones, las obsesiones o los comportamientos repetitivos pueden verse como un intento de reestructurar fracasos en la vinculación, de dar significado y mejorar la predictibilidad basándose en elementos del pasado y de protección frente a nuevos traumas (12). Según describe Csikszentmihalyi (13), «la mente errante se ocupa usualmente con pensamientos negativos, y este sesgo pesimista es adaptativo en el sentido de que aumenta las posibilidades de supervivencia al mejorar así la anticipación de situaciones peligrosas».

Desde un punto de vista de estrategia evolutiva, los pensamientos obsesivos después de la muerte traumática de un ser querido, son una respuesta de supervivencia cuya función tiene que ver con la mejora de la predictibilidad ante la realidad de la muerte. En la obsesión, la fantasía es poder retroceder en el tiempo y hacer que las cosas sean de otra manera, ejerciendo así un intento de control: como esto no es posible físicamente, se hace mentalmente. El cerebro debe mejorar sus funciones de observación para evitar la repetición del trauma, por tanto la mente repasa los detalles de las circunstancias de la muerte una y otra vez con la esperanza de hallar elementos o detalles que faciliten una mejor comprensión de la historia. Así el pensamiento obsesivo aparece como una defensa cognitiva sobre la que el doliente se apoya para poder poner orden y mejorar la predictibilidad de posibles nuevas experiencias de pérdidas afectivas traumáticas.

Por otra parte, la obsesión en forma de culpa tiene una función psicológica reparativa. Los pensamientos de culpa actúan como un introyecto interno de crítica para evitar la crítica externa; es una forma de evitar el miedo a no ser perfectos, a haber hecho algo malo y a ser acusados de negligencia, una forma de autocastigo con una función expiativa del daño: «Sentirme culpable de su muerte por no haberme dado cuenta antes de su enfermedad es una manera de sentir que sigo siendo una buena madre». «Si no estuviera obsesionado sobre el porqué de su muerte significaría que la acepto, y eso significaría que no le quiero». 
No aceptar la realidad de su muerte y luchar contra lo que parece ser su causa es un intento de seguir siendo un buen padre o una buena madre protectora. Estar obsesionando tiene la función de seguir cuidándole. Si la persona en duelo no se sintiera culpable, posiblemente sentiría que no es buena persona. La obsesión permite mantener la integridad y perdonarse a sí mismo, una forma de seguir siendo fiel a la relación. De la misma manera, las obsesiones de fantasías de venganza desde la culpabilización de otro por las circunstancias de la muerte tendrían también la función de esfuerzo compensatorio por el fracaso en el rol protector: «no puedo estar en paz hasta que hayamos encontrado al culpable».

También rumiando se cumple otra necesidad relacional, que es la de garantizar la continuidad en la relación con la persona fallecida. Mientras la persona en duelo está obsesionándose mantiene un nivel de contacto con su ser querido ausente. Fantasear acerca del desaparecido es una forma de estar vinculado con el pasado, una manera de evitar sentir la experiencia emocional de la muerte. En este sentido cumple una función psicológica estabilizadora que protege del flujo de emociones incómodas que acompañan la regresión (14).

Turner y otros (15), en su trabajo sobre los factores biológicos en los comportamientos obsesivos, concluyen que estos podrían verse como una respuesta o consecuencia a estados afectivos de sobreexcitación subyacente. Las personas en duelo, cuando están obsesionando o expresando sus pensamientos obsesivos, presentan un alto nivel de sobreexcitación psíquica, que aparece como un estado de ansiedad generalizada. Es posible entonces que las rumiaciones sean una consecuencia de este estado de sobreexcitación generado por la ruptura del vínculo de seguridad afectiva, como un intento de recuperar el sentido de control sobre la experiencia emocional de trauma. Las obsesiones interrumpen el contacto interno con los propios sentimientos, sensaciones y recuerdos demasiado dolorosos. En situaciones de estados emocionales complejos relacionados con acontecimientos traumáticos, la activación de respuestas rumiativas podría favorecer el procesamiento de esas emociones difíciles (16).

La rumiación es una manera de estar en la periferia del dolor del duelo, en la abstracción de la idea de la pérdida, o en el conflicto y las dudas acerca de las causas, pero no en la experiencia real de la muerte. En este sentido, las obsesiones funcionan como una defensa para no permitir la emergencia de sentimientos dolorosos amenazadores. Las emociones presentes más aparentes son enfado y culpa, que aparecen en forma de obstinación recurrente, persistencia y rigidez y resentimiento, y no en su forma natural espontánea. No hay contacto real con el objeto psicológico del enfado.

«No me lo puedo quitar de la cabeza. No pude decirle adiós... No puedo quitarme de la cabeza que no fuera su cuerpo. Mi hijo murió en un accidente de avión, 
ORIGINALES Y REVISIONES

pero se equivocaron y no era él: me entregaron otro cuerpo así que en el funeral que le hicimos él no estaba ahí. Estoy enfadada, pero no sé con quién, con los políticos supongo. Tengo una pena muy grande. Ahora voy a otra iglesia, no puedo acercarme a mi parroquia: no puedo dejar de pensar que no nos pudimos despedir de él. Hace ya más de un año». Esther.

Estar de forma cognitiva en el espacio de ¿cómo?, ¿cuándo? y ¿por qué? es una forma de mantenerse alejado del dolor real de la ausencia, de la experiencia subjetiva de la soledad. En este sentido, las obsesiones son mecanismos de defensa evitativos que protegen de la emergencia de sentimientos dolorosos amenazadores. Esta función protectora o de evitación del dolor real del duelo da un sentido de estabilidad y control del dolor: «si no estuviera obsesionada acerca de mi enfado o mi culpa estaría deshecha por el dolor, me hundiría».

La muerte de un ser querido produce en ciertas personalidades vulnerables una fragmentación interior donde las obsesiones pueden aparecer como un intento de compensar esta falta de estructura interna. Para personalidades con un funcionamiento estructural que está en un nivel límite de desorden, los comportamientos o pensamientos obsesivos funcionan como un ancla donde sujetar su fragilidad interna, como una forma de compensar experiencias personales que de otra manera serían caóticas. La rigidez de la estructura del pensamiento obsesivo genera un mayor sentido del yo y de seguridad (11). En este sentido, los pensamientos rígidos y rutinarios tendrían una función de estabilidad y protección de un ego frágil, inmaduro y dependiente.

«No puedo dejar de pensar en mi papá, estoy casada feliz pero mi papá era el hombre más importante de mi vida. Nos llamábamos cada día y le consultaba todas mis decisiones. No puedo pasar sin él, estoy muy ansiosa y no dejo de pensar en él. Le necesito. Aún ahora me sentaba en sus rodillas y me decía que yo era su niña. ¿A quién contaré ahora mis problemas? Me siento abandonada, no soy capaz de tirar adelante. No acepto que haya muerto, no me lo puedo creer. Espero cada día a que me llame». Marina.

Por último, el pensamiento obsesivo tiene la función de defensa ante la fragmentación interna producida por la muerte del ser querido. La tesis descrita en el modelo de adaptación al trauma de Janoff-Bulman (17) explica cómo estos eventos traumáticos sacuden y ponen en crisis el conjunto de valores, presuposiciones sobre la vida, creencias afectivas, sociales y valores que mantienen a las personas integradas. Un afrontamiento adaptativo es aquel que contribuye a integrar estas experiencias traumáticas en la visión personal del mundo y le dan un sentido, asimilando el acontecimiento traumático y otorgándole un significado. Este modelo tiene su aplicación en el ajuste al duelo $(6 ; 18 ; 19 ; 20)$, 
donde la pérdida de vínculos afectivos, especialmente cuando es traumática, cambia la percepción personal del mundo. Es ahí donde el pensamiento obsesivo aparece como un intento de construir una cohesión interna, de recuperar el control, de aceptar la fragilidad de la vida, en una búsqueda de perfeccionismo ante el caos que supone la muerte, contribuyendo al desarrollo de un nuevo encuadre de referencia que incluya la fragilidad e inconstancia de la vida y de las relaciones.

\section{Factores de riesgo de pensamientos obsesivos}

Situacionales: Percepción de que la muerte era evitable y/o fortuita.

Percepción de falta de información sobre las circunstancias de la muerte.

Circunstancias de la muerte son traumáticas y/o desautorizadas.

Muertes que destruyen constructos de seguridad.

Personales: Personas con vulnerabilidad obsesiva previa.

Interpersonales: Relaciones codependientes donde la muerte supone una amenaza a la protección y seguridad.

Los factores de riesgo son predictores asociados a una mayor posibilidad de que se instalen mecanismos obsesivos como estilos de afrontamiento del duelo. Los factores de riesgo en el duelo suelen ser aspectos de la personalidad del doliente, o más específicos del duelo, como las circunstancias de la muerte o las características de la relación con la persona fallecida. La posibilidad de describir factores de riesgo de aparición de pensamientos obsesivos es importante porque puede mejorar la identificación de colectivos más vulnerables, puede favorecer una respuesta social más adecuada y preventiva y a la vez da pistas sobre posibilidades de tratamientos efectivos. No todas las personas en duelo responden a la pérdida con pensamientos obsesivos y para la minoría que lo hace es importante poder detectar qué factores propician este estilo de afrontamiento y en cuáles la posibilidad de que se instalen, de forma rígida y mal adaptativa, es mayor.

Según la teoría de la vinculación, la pérdida súbita de la figura de vinculación destruye los constructos de seguridad y el ajuste a la nueva situación parece ser mucho más difícil o estresante que cuando la muerte es anticipada, por ejemplo tras una enfermedad larga. Es en estas situaciones de no anticipación, especialmente si las circunstancias han sido traumáticas, donde parece que la prevalencia del pensamiento obsesivo es mayor. Un caso específico son las situaciones donde el doliente percibe que la muerte podía haberse evitado -por ejemplo, en una supuesta situación de negligencia médica, o en un accidente doméstico- y que 
ORIGINALES Y REVISIONES

va a causar la posible fijación obsesiva de pensamientos alrededor del cúmulo de circunstancias que llevaron a la muerte.

Cuando el doliente carece de información adecuada sobre las circunstancias y hechos que rodearon la muerte, éste va a tener que imaginar todo o parte de lo sucedido. En estas situaciones parece despertarse la obsesión desde la fantasía, que recorre una y otra vez las distintas posibilidades de lo ocurrido, siendo el resultado un estado de hiperexcitación vigilante que alimenta el pensamiento obsesivo.

Con respecto a los factores de riesgo personales, parece plausible que aquellas personalidades perfeccionistas, exigentes y con tendencia a la personalidad obsesiva sean a su vez más susceptibles de responder a una pérdida con pensamientos obsesivos. De la misma manera que personalidades frágiles e inseguras y con dificultades respecto al control de sus vidas, o personalidades inmaduras que nunca han contemplado, ni tienen integrado el hecho de la muerte, o la posibilidad de la pérdida, van a tener muchas más dificultades de adaptación respondiendo desde niveles altos de ansiedad asociados a rumiaciones obsesivas. Nolen-Hoeksema y otros (21) señalan que las personalidades con vinculaciones ambivalentes suelen ser más susceptibles de tener duelos crónicos que se alargan en el tiempo y con una tendencia a estilos rumiativos.

\section{Implicaciones para la intervención terapéutica}

La provisión de distracciones, o el darles instrucciones a los dolientes de que simplemente dejen de pensar en ello, o de tener emociones negativas, son intervenciones desde modelos cognitivo-conductuales que en situaciones de depresión parecen producir un mejoramiento temporal de los síntomas, pero que no son efectivas en personas en duelo (5). «No pienses en ello, distráete» parece la intervención terapéutica más simple y lógica, pero la posibilidad de controlar el pensamiento obsesivo de forma cognitiva no es tarea fácil: la mente no puede parar a más mente. La invitación a utilizar esfuerzos cognitivos para detener el pensamiento obsesivo acrecienta aún más y fija las rumiaciones. Según Erskine (22) las aproximaciones intelectuales o la confrontación directa sólo logran aumentar la ansiedad de la persona y su sentido de inadecuación, posiblemente incrementando aún más el esfuerzo defensivo de mantener lo que es inconsciente lejos del alcance del consciente. Como muy bien describen las personas en duelo: «cuánto más intento dejar de pensar en ello, más me obsesiono y no puedo parar de darle vueltas».

Desde la visión de la Psicoterapia Integrativa, las obsesiones, fantasías recurrentes y preocupaciones repetitivas ante situaciones de trauma deben verse como 
respuestas naturales de orden psicológico, emocional cognitivo o conductual que la persona utiliza de forma inconsciente para reducir o aliviar el dolor y el sufrimiento (23). Por tanto la exploración de estos mecanismos como defensas nos da una oportunidad de identificar su función psicológica o relacional, para que pueda así ser tratada de forma efectiva en el marco de la relación terapéutica.

Esta mirada adaptativa de los mecanismos o estilos de afrontamiento tiene implicaciones importantes para la terapia de duelo. El pensamiento obsesivo no debe interpretarse como una conducta patológica, sino como un intento natural del inconsciente de adaptarse al dolor de la pérdida y satisfacer alguna de las necesidades relacionales específicas que aparecen tras la muerte de un ser querido. A pesar de que son pensamientos disruptivos, en el sentido de que rompen el contacto interno o el interpersonal, el terapeuta debe acogerlos como una adaptación creativa a la ruptura del vínculo afectivo. Lo que necesitamos es una psicoterapia intrapsíquica y relacional, cuyo objetivo no sea simplemente suprimir el pensamiento obsesivo, sino comprenderlo, poner nombre a su función psicológica, validarlo y buscar maneras de responder a las necesidades subyacentes. Todo ello mediante una respetuosa indagación en la experiencia fenomenológica de la persona en duelo que acoja su vulnerabilidad natural, facilite de forma respetuosa la disolución de las defensas y la integración de los aspectos fragmentados.

En una primera etapa del tratamiento va a ser esencial la escucha atenta sobre la experiencia subjetiva de la obsesión: animarle a expresar en voz alta sus preocupaciones, pensamientos repetitivos, rumiaciones, y hacerlo en forma de diálogo con el terapeuta, que muestra interés, anima y promueve la expresión completa de los pensamientos, valida la experiencia y comparte sus emociones, permitiéndose ser genuinamente impactado por lo que está oyendo. Haciendo esto el terapeuta ofrece una experiencia de comprensión y de compartir que mitiga la soledad y el sentimiento de aislamiento del doliente y a la vez permite el despliegue total de las fantasías y cuestiones alrededor de las cuales se configura la obsesión.

La persona en duelo entonces expresa en voz alta sus deseos, sus miedos, sus preguntas sin respuesta, sus fantasías de venganza, o de reparación, su sentimiento de culpa, y lleva al consciente y experimenta en el contexto de la relación terapéutica estas cogniciones nunca antes compartidas, que son recibidas y acogidas con sensibilidad e interés por parte del terapeuta.

«Háblame de todos estos pensamientos, ideas y fantasías que pasan por tu cabeza por la noche (dímelo a mí, mírame a los ojos)... Parece que estás exhausta de tanto darle vueltas... Cuéntame a qué das vueltas... ¿Cómo te sientes con este monólogo interior? ¿Sola?... Háblame de tu soledad... ¿A quién te gustaría decirle todo esto?... ¿Quién te gustaría que te estuviera escuchando?». 
ORIGINALES Y REVISIONES

Al permitir esta experiencia, que incluye a la vez aspectos cognitivos y de expresión de afectos dentro del proceso terapéutico, se facilita el cambio, pues el terapeuta está proveyendo al paciente de una experiencia integradora de estos aspectos antes disgregados, que le proveen de un nuevo sentido del yo (24-25).

La experiencia de los pensamientos obsesivos siempre está fuera de la realidad: en el allá y antes o después. Es por ello que una estrategia terapéutica importante a utilizar es la indagación fenomenológica, una de las estrategias básicas de la Psicoterapia Integrativa (26). La exploración en el aquí y ahora, del pensamiento obsesivo es fundamental: animar al doliente a que hable despacio, conectando visualmente con el terapeuta, respirando después de cada expresión, parando, poniendo palabras a las sensaciones físicas, describiendo y siendo consciente de la rigidez corporal, y de cómo la mirada se retira del contacto visual.

En las situaciones donde los pensamientos obsesivos tienen que ver con el recorrido de las circunstancias de la muerte, que el doliente recrea en su mente una y otra vez, la indagación va a permitir una cuidadosa exploración sobre los detalles, los sentimientos expresados y los negados, el apoyo recibido y el apoyo necesitado y no satisfecho, todo ello acompañado desde la sensibilidad y empatía del terapeuta, que va a facilitar la reescenificación de los elementos traumáticos que rodean la muerte del ser querido y va a apoyar y sostener la expresión emocional de dolor asociada.

«Cuéntame, ¿cómo fue la muerte, dónde estabas cuando te dieron la noticia? ¿Qué pasa por tu cabeza cuando piensas en esos días? ¿Con quién pudiste hablarlo? ¿Con quién hubieras necesitado poder hablar y no pudiste? ¿Qué información te dieron? ¿Qué información no te dieron y necesitabas? ¿Dónde fuiste? ¿Cómo te sentiste? ¿Cómo pudiste expresar tus sentimientos? ¿Qué te sostuvo? ¿Qué ayuda no tuviste? ¿Qué crees que podría haber sido distinto? Si eso hubiera sido así de distinto, ¿en qué te hubiera ayudado?».

En otras situaciones los pensamientos obsesivos tienen que ver con fantasías de venganza respecto a la posible causa de la muerte. El doliente imagina situaciones donde el supuesto responsable sufre un castigo; puede estar incluso fantaseando con la posibilidad de matar o desear la muerte al que cree que es el culpable de lo que sucedió, como un intento de reparar la culpa del peso de la responsabilidad en el fracaso de la protección. Estos pensamientos intrusivos pueden ser muy alarmantes para el doliente. Esta fantasía es lógica y natural, pero la persona no se atreve a expresarla en voz alta por lo irracional, con lo que siente a la vez más culpa y por tanto reprime su deseo, se agita y deja el sueño de la venganza en lo simbólico y con ello aumenta el pensamiento obsesivo. El no poder ponerle palabras no hace sino reactivar el cúmulo de emociones complejas que son la base de la confusión y la ansiedad. 
Cuando este sueño es expresado verbalmente, y validado como humano y natural por el terapeuta sensible y empático, entonces éste puede llevar al paciente a la conclusión imaginada, y juntos deben explorar la fantasía de alivio del dolor. El ponerle palabras facilita la expresión de las emociones subyacentes que pueden ser identificadas una a una: entonces la confusión y agitación son sustituidas por la rabia, el enfado y el resentimiento, que a su vez son sustituidos por el dolor, la tristeza y el amor. En este camino de clarificación emocional la ansiedad va desapareciendo como defensa evitativa y emergen las emociones hasta ahora reprimidas por inaceptables y dolorosas.

Un ejemplo de este camino de clarificación que puede durar varias sesiones sería: «Me dices que estabas fantaseando sobre la muerte de X... ¿Qué has imaginado?... ¿Cómo has pensado en hacerle daño?... ¿Puedes contarme hasta dónde has pensado en tu imaginación? Dices que te imaginas cogiendo la escopeta y yendo a su casa,... ¿qué más has imaginado?... ¿Qué has imaginado que harías al llegar a su casa?... Y después de disparar, ¿qué verías?... ¿Cómo sería la imagen ante ti?... ¿Cómo te sentirías al verlo muerto ahí?... Aliviada... ¿Aliviada de qué?... ¿Qué es lo que tú crees que aliviaría la muerte de este hombre (conductor que atropelló a tu hijo)? Crees que aliviaría tu dolor, ¿verdad?..., Háblame de tu dolor...(enfado)».

Una psicoterapia intrapsíquica y relacional -en vez de cognitiva y conductual-, basada en la indagación respetuosa de la fantasía de venganza, va a fomentar la expresión verbal y emocional del pensamiento obsesivo, validando su función de protección. En el apoyo y la comprensión del terapeuta, el paciente encontrará el alivio y la satisfacción de la necesidad relacional escondida. Y es entonces, una vez ha sido facilitada la regresión, cuando éste puede escuchar, comprender y dar sentido a su fantasía: que va a ser validada por el terapeuta: «entiendo que lo que más lamentas es no haber podido proteger a tu hijo y que pensando en matar a $X$ lo que estás expresando es tu deseo profundo de que eso no hubiera sucedido y tu sentimiento de culpa y dolor».

Una vez expresada y acogida la obsesión e identificada su función psicológica, el objetivo terapéutico es disolver esta defensa cognitiva para que puedan emerger los sentimientos dolorosos o incómodos subyacentes. La estructura rumiativa es una defensa contra la ansiedad del trauma, siendo la causa de esta ansiedad la represión de los sentimientos de dolor, enfado o culpa. La obsesión funciona como una maniobra cognitiva para evitar los sentimientos conflictivos. En el dialogo y el contacto empático con el terapeuta, el pensamiento circular o repetitivo se rompe y el doliente tiene la posibilidad de conectar y expresar esos sentimientos escondidos. Juntos pueden poner nombre a esos sentimientos incómodos de dolor, enfado o culpa, proveyendo experiencias de insight donde la persona en duelo podrá llegar a entender las motivaciones inconscientes de esta defensa. 
ORIGINALES Y REVISIONES

A veces las obsesiones toman forma de fijaciones o focalizaciones en detalles sobre la relación, o aspectos de las circunstancias de la muerte, aparentemente irrelevantes, pero en los que el doliente concentra toda su atención obsesiva perdiendo la visión general del todo. Es importante no confrontar este tipo de obsesión, sino más bien intentar entender la historia de la persona y la función intrapsíquica de la fijación. Detrás de este detalle hay algo importante, una tarea de duelo, un asunto pendiente de relación, o una necesidad relacional no satisfecha, o una función evitativa que debe ser identificada y explorada.

Las fijaciones obsesivas en detalles de las circunstancias de la muerte a veces se originan por la falta de elementos necesarios para la comprensión de lo sucedido. En el contexto terapéutico deben poderse explorar todos los detalles del evento traumático y las conclusiones distintas y sentimientos posibles. Si esto no es suficiente, a veces es necesario recabar la información adecuada que permita al doliente comprender lo sucedido. La necesidad de tener información sobre los hechos es un derecho natural del doliente. A menudo se hace necesaria una intervención institucional reparativa por parte de los responsables correspondientes. El terapeuta de duelo debe estar entrenado para preparar y coordinar estas entrevistas entre representantes políticos, directores de empresas o instituciones, o miembros del cuerpo de seguridad, entre otros, donde el doliente pueda tener respuesta a todas sus preguntas.

Una vez escuchada y validada la obsesión en un espacio de protección, seguridad y confianza, y explorados los sentimientos negados mediante la indagación fenomenológica, entonces, en una segunda fase de la terapia, las estrategias cognitivas como por ejemplo la estructuración del tiempo, los compromisos de conductas o la identificación de acciones reparadoras pueden ser eficaces. Las prescripciones cognitivas deben venir siempre en una etapa posterior del proceso terapéutico, cuando el nivel de insight es más alto y la relación terapéutica más profunda. Una vez identificada la necesidad relacional que subyace bajo la obsesión, se invita al doliente a encontrar una nueva manera de satisfacer esta necesidad que sea en forma de conducta compensadora; y que se comprometa a ella. «¿De qué manera podrías encontrar un gesto o símbolo o acción que mostrara tu deseo de seguir amándole, o de manifestar tu sentido de culpa?». De forma espontánea muchos gestos de sublimación tienen este sentido reparativo.

El trabajo terapéutico del pensamiento obsesivo lleva gradualmente a la persona a la aceptación de la fragilidad e impredictibilidad de la vida. La fantasía de control detrás de las rumiaciones es la anulación de la infinitas posibilidades que nos ofrece la aventura de la vida; la omnipotencia de la mente frente a la aceptación de la limitación de los seres humanos, y nuestra incapacidad de protección total de nuestros seres queridos. Una madre no puede vigilar a un niño las 24 horas 
del día, como tampoco se puede controlar a una persona en depresión durante cada minuto de su vida; la muerte es impredictible. Para mantener esta garantía de control, deberíamos encerrar a nuestros seres queridos en habitaciones blindadas, pero esto supondría anular la espontaneidad de su existencia, de la libertad en las relaciones, de la autonomía natural de las personas. La resolución del pensamiento obsesivo contribuye a entender la propia historia personal y ver las pérdidas como parte integral de la propia vida y no como algo a rechazar: aceptarlas como algo inevitable y a la vez como una oportunidad de crecer, madurar y expandir la conciencia personal, y la responsabilidad e implicación en la vida.

\section{Conclusiones}

Los pensamientos obsesivos se caracterizan por su repetitividad, circularidad, fijación y falta de visión general. Ante la pérdida de un ser querido, estos pensamientos se configuran como cuestiones alrededor de las circunstancias de la muerte, las posibles causas y efectos de la pérdida, aspectos de la relación con el ser querido, algunos de los síntomas de duelo y sus consecuencias: «¿Qué me ha pasado? ¿Por qué el mundo es así? ¿Qué es la muerte? ¿Quién soy yo sin él/ella? ¿Qué será de mi vida?».

Este proceso cognitivo permite una revisión exhaustiva del evento traumático y sus consecuencias en la vida de la persona en duelo. Como estructura defensiva psicológica tiene varias funciones: mejorar la predictibilidad de posibles nuevas situaciones de pérdida traumática, dar significado a lo sucedido, reparar los sentimientos de culpa, mantener continuidad en la relación con la persona fallecida, manejar emociones dolorosas como son el enfado y el dolor, y dar un sentido de protección y estabilidad dentro de la fragmentación interna que la persona en duelo vive.

Para la mayoría de las personas este estilo de afrontamiento es una respuesta natural adaptativa al duelo que se resuelve favorablemente. Las personas en duelo pueden por sí mismas encontrar las respuestas y satisfacer las necesidades subyacentes, con lo que, con el tiempo se produce una disminución de la actividad obsesiva dedicada a procesar la experiencia, se mitiga la sintomatología y los pensamientos pierden su calidad intrusiva y perturbadora, de manera que la persona se ajusta a la pérdida y puede empezar a centrarse en su futuro. En estos casos el pensamiento obsesivo es adaptativo y predice un buen resultado de duelo, una mejora y bienestar progresivo en el doliente.

Pero si éste no es capaz de entrar en contacto, identificar y explorar estas funciones del pensamiento obsesivo, y por tanto las necesidades intrapsíquicas o 
interpersonales no se satisfacen, entonces los pensamientos se vuelven intrusivos, disruptivos, y el proceso cognitivo se convierte en una rumiación maladaptativa, tal y como es descrita por Nolen-Hoeksema en su modelo $(5 ; 27)$. La persona no puede desarrollar un nuevo encuadre de referencia que incluya la pérdida y sus consecuencias. Es en estas situaciones cuando los pensamientos intrusivos dolorosos se intensifican y cronifican en el tiempo sin remisión, dando lugar a un pobre resultado de duelo.

El terapeuta no hará intervenciones dirigidas simplemente a desactivar el estilo rumiativo que presenta el doliente, como si fuera un rasgo maladaptativo a evitar, sino que estará más interesado en identificar, validar y explorar el pensamiento obsesivo como estructura psíquica defensiva adaptativa ante el sufrimiento natural del duelo, y la acogerá como una oportunidad de identificar y elaborar aspectos o tareas duelo subyacentes que generan conflicto intrapsíquico y fragmentación interna. Para ello la relación terapéutica (26) va a ser una herramienta esencial.

Es necesaria una investigación futura que identifique y describa qué es lo que hace que los pensamientos obsesivos sean o no productivos. Detectar factores de riesgo de complicaciones en la resolución del pensamiento obsesivo es fundamental: estos factores deben incluir aspectos situacionales, personales e interpersonales y a la vez contemplar otras posibles funciones psicológicas de estos pensamientos más allá de la búsqueda de significados.

La psicoterapia del duelo, y de forma específica el tratamiento del pensamiento obsesivo, se enfrenta a un buen número de retos distintos y nuevos para los que los métodos y estrategias clásicas de psicoterapia no van a ser útiles. El duelo es un problema que no tiene solución y que produce un sufrimiento emocional agudo en la persona que lo vive. La pérdida de la relación es la pérdida del contacto con el otro, que a su vez rompe el contacto interno con uno mismo. Es una experiencia de fragmentación traumática de la identidad, producida por la ruptura de un vínculo afectivo. La psicoterapia integrativa ofrece un modelo donde justamente la relación terapéutica es un elemento central. Esta relación es utilizada por el terapeuta para promover el contacto interpersonal que producirá el cambio, a través de la elaboración de los conflictos intrapsíquicos y promoviendo la integración del ego fragmentado. 


\section{BIBLIOGRAFÍA}

(1) LaZarus, L.; Folkman, S., Stress, Appraisal and Coping, Nueva York, Springer, 1984.

(2) Moss, R. H.; SCHAEFER, J. A. «Life Transitions and Crisis: A Conceptual Overview», en R. H. Moss \& J. A. Schaffer (eds.), Coping with Life Crisis: An Integrative Approach, 1986, pp. 3-28.

(3) Nolen-Hoeksema, S., «Responses to Depression and their Effects on the Duration of Depressive Episodes», Journal of Abnormal Psychology, 1991, 100, pp. 569-582.

(4) Nolen-Hoeksema, S.; Parker, L. E.; Larson, J., «Ruminative Coping with Depressed Mood following Loss», Journal of Personality and Social Psychology, 1994, 67, pp. 92-104.

(5) Nolen-Hoeksema, S , «Ruminative Coping and Adjustment to Bereavement», en M. S. Stroebe, R. O. Hansson, W. Stroebe, H. Schut (eds.), Handbook of Bereavement Research: Consequences, Coping, and Care, Washington DC, American Psychology Association, 2001, pp. 545-562.

(6) Bower, J. E.; Kemeny, M. E.; Taylor, S. E.; Fahey, J. L., «Cognitive Processing, Discovery of Meaning, CD 4 Decline and AIDS -Related Mortality Among Bereaved HIV-Seropositive Men», Journal of Consulting and Clinical Psychology, 1998, 66, pp. 979-986.

(7) Calhoun, L. G.; Tedeschi, R. G., «Post Traumatic Growth: Future Direction», en R. G. Tedeschi, C. L.; Park, L. G.; Galhoun (eds.), Posttraumatic Growth: Positive Changes in the Aftermath of Crisis, Mahwah, N. J., Lawrence Erlbaum, 1998.

(8) Michael, S. T.; SNYder, C. R., «Getting Unstuck: the Roles of Hope, Finding Meaning, and Rumination in the Adjustment top Bereavement among College Students», Death Studies, 2005, 29 , pp. $435-458$.

(9) Tinberger, N., Social Behaviour in Animals, Londres, Chapman \& Hall, 1953.

(10) Horowitz, M.; Marmor, C.; Krupnick, J.; Wilner, N.; Kaltreider, N.; WallersTEIN, R., Personality Styles and brief Psychotherapy, Nueva York, Basic Books, 1984, pp. 160-161.

(11) Johnson, S. M., Character Styles, Nueva York, Norton, 1994, p. 270.

(12) ERSKINE, R. G., «The Therapeutic Relationship: Integrating Motivation and Personality Theories», en R. G. ERSKINE, Theories Methods of an Integrative Transactional Analysis: A Volume of Selected Articles, San Francisco, TA Press, 1997, pp. 7-19.

(13) Csikszentminalyi, M., The Evolving Self: A Psychology for the Third Millennium, Nueva York , Harper Collins, 1993.

(14) ERskine, R. G., «Psychological Function, Relational Needs, and Transferential Resolution: Psychotherapy of an Obsession», Transactional Analysis Journal, 2002, 31, 4, pp. 220 226.

(15) Turner, J.; Beidel, D.; NAthan, R., «Biological Factors in Obsessive-compulsive Disorder», Psychological Bulletin, 1985, 97, pp. 430-450.

(16) HERVÁs, G.; VÁZQUEZ, C., «Explorando el origen emocional de las respuestas rumiativas: el papel de la complejidad emocional y la Inteligencia Emocional», en Ansiedad y estrés, 2006, 12 (2-3), pp. 279-292.

(17) Janoff Bulman, R., Shattered Assumptions: Towards a New Psychology of Trauma, Nueva York, Free Press, 1992.

(18) Stein, N.; Folkman, S.; Trabasso, T.; Richards, T. A., «Appraisal and Goal Processes as Predictors of Psychological Wellbeing in Bereaved Caregivers», Journal of Personality and Social Psychology, 1997, 72, pp. 872-884.

(19) NeymeYer, R., «Widowhood, Grief and the Quest of Meaning: A Narrative Perspective on Resilience», en D. CARR, R. M. Nesse, C. B. Wortman (eds.), Late Life Widowhood in the United States. Nueva York, Springer, 2005.

(20) Gillies, J; NeimeYer, R. A., «Loss, Grief, and the Search for Significance: Towards a Model of Meaning Reconstruction in Bereavement», Journal of Constructivist Pyschology, Routledge, 2006, 19, pp. 31-65. 
ORIGINALES Y REVISIONES

(21) Nolen-Hoeksema, S.; Mc Bride, A.; LARSON, J., «Rumination and Psychological Distress among Bereaved Parents», Journal of Personality and Social Ssychology, 1977, 72, pp. 855-862.

(22) ERskine, R., Apuntes docentes no publicados, Madrid, 2002.

(23) Moursund, J.; ERskine, R., Integrative Psychotherapy: the Art and Science of Relationship, Thomson (eds.), 2004.

(24) Greenberg, L. S.; Rice, L. N.; Elliot, Facilitando el cambio emocional: el proceso terapéutico punto por punto. Paidós, 1996.

(25) GREenBerG, L. S.; KoRMAn, L., «Assimilation Emotion into Psychotherpay Integration», Journal of Psychotherapy Integration, 1993, 3.

(26) Erskine, R.; Moursund, J.; Trautmann, R., Beyond Empathy: A Therapy of Contact in Relationship, Brunner Mazel (eds.), 1999.

(27) TAIT, R.; SILVER, R. C., «Coming to Terms with Major Events Negative Life Events», en J. S. Uleman \& J. A. BARGH (eds.), Unintended Thought, 1989, pp. 351-382.

* Alba Payás Puigarnau. Psicoterapeuta. Servicio de Apoyo al Duelo.

Correspondencia: Santa Eugenia 79, 17006 Girona. apayas@grn.es; serveidol@girona.es tf. 972.244441.

** Fecha de recepción: 11-XII-2007 (aceptado el 14-IV-2008). 